\title{
REACTIVITY OF SUBSTITUTION ELEMENTS
}

WORK PERFORMED UNDER

AEC CONTRACT No AT (30-3) -326

Issued January 19, 1959

- Dr. R. L. Murray

North Carolina State College

Raleigh, North Carolina

Consultant

Alco Products, Ine. Post Office Box 414

Schenectady, $\mathrm{N}_{\mathrm{O}}$ 


\section{DISCLAIMER}

This report was prepared as an account of work sponsored by an agency of the United States Government. Neither the United States Government nor any agency Thereof, nor any of their employees, makes any warranty, express or implied, or assumes any legal liability or responsibility for the accuracy, completeness, or usefulness of any information, apparatus, product, or process disclosed, or represents that its use would not infringe privately owned rights. Reference herein to any specific commercial product, process, or service by trade name, trademark, manufacturer, or otherwise does not necessarily constitute or imply its endorsement, recommendation, or favoring by the United States Government or any agency thereof. The views and opinions of authors expressed herein do not necessarily state or reflect those of the United States Government or any agency thereof. 


\section{DISCLAIMER}

Portions of this document may be illegible in electronic image products. Images are produced from the best available original document. 


\section{DISTRIBUTION}

Copies

$1-2$

New York Operations Office

U. S A tomic Energy Commission

70 . Columbus Avenue

New York 23 , New York

ATTENTION: Capt Richard L. Harris

(V. J. Del Vecchia for C)

3-4 U. Atomic Energy Commission

Washington 25, D. C

ATTENTION: Classified Technical Library for Co1. D. G. Williams

$\mathrm{U}, \mathrm{S}$ Atomic Energy Comission

Army Reactors Branch

Division of Reactor Development

Washington 25, D, C.

ATTENTION: Major Paul H Egis

8

U. S Atomic Energy Commission

Chief $f_{\text {s }}$ Patents Branch

Washington $25, \mathrm{D}$. C.

ATTENTION: Roland A Anderson

U.S. Atomic Energy Commission

Chicago Operations office

P. 0. Box 59

Lemont, Illinois

ATTENTION: Captain J Schweizer

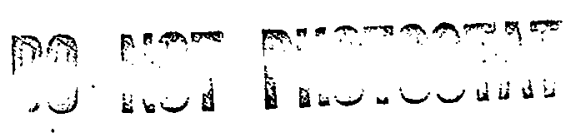




\section{DISTRIBUTION (CONT'D)}

Copies

10 U. S. Atomic Energy Commission

Idaho Operations office

Phillips Petroleum Company, NRTS

Technical Library

P. O. Box 1250

Idaho Fa11s, Idaho

ATTENTION: Major Robert L̇. Ednie

11 Nuclear Power Field office

USERDL

Fort Belvoir Virginia

ATTENTION: Major W. R. Wray

12. Union Carbide Nuclear Corporation Oak Ridge National Laboratory

Y-12 Building 9704-1

P.O. Box "Y"!

Oak Ridge, Tennessee

ATTENTION: A. L. Boch

13 District Engineer, Alaska District

Ư.S. Army Corps of Engineers

P. 0. , Box 7002

Anchorage, Alaska

ATTENTION: NPAVG-N

14 The Martin Company

P. O. Box 5042

Middle River, Maryland

ATTENTION: AEC Contract Document Custodian

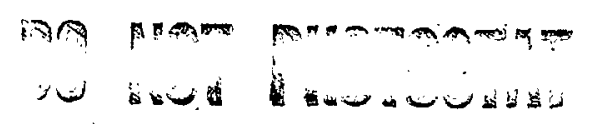




\section{DISTRIBUTION (CONT'D)}

\section{Copies}

$15-39$

U. S. Atomic Energy Commission

Reference Branch

Technical Information Services Extension

P. 0, Box 62

Oak Rídge, Tennessee

$40 \div 41$

Alco Products, Inc.

P. 0 . Box 145

Fort Belyoir, Virginia

ATTENTION: H: L : Weinberg

$42-50$

Alco Products, Inc.

Post office Box 414

Schenectady, N.Y.

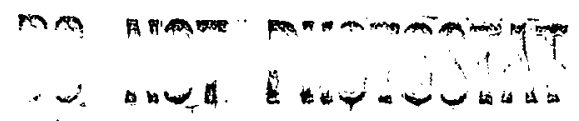




\section{Reactivity of Substitution Elements}

Raymond L. Murray

Introduction.

A method is sought for predicting the reactivity differences between fuel elements attached to control absorbers and fixed fuel elements. (It is assumed that a simple method, readily understood and applied is of immediate interest.) The approach described in this report is based on a logic that is admittedly approximate, and which should be subjected to experimental check.

Physical Situations and Analysis.

There are several cases of interest, corresponding to various orientations of the control fuel element involved, and of the remaining control elements.

Case A. All control rods but one are fully inserted in the core; one control element is pulled out, thus introducing what will be designated as a follower fuel element. A sketch of the arrangement is shown in Figure 1. Experimental measurements can be and have been made for this case. It is found that substitution experiments yield a good fit to the $\mathrm{J}_{0}^{2}$ weighting. Calculations for the center line rod by two group, three region (core, element and reflector) are available, * and agree reasonably, well with experiment. This success leads one to presume that in the region of the reactor containing other control absorbers that the flux is effectively a chopped Bessel function. This assumption will be assumed to include the special case of a bank region.

* APAE-27, page $89 \mathrm{ff}$. 


\section{Figure $1_{0}$}

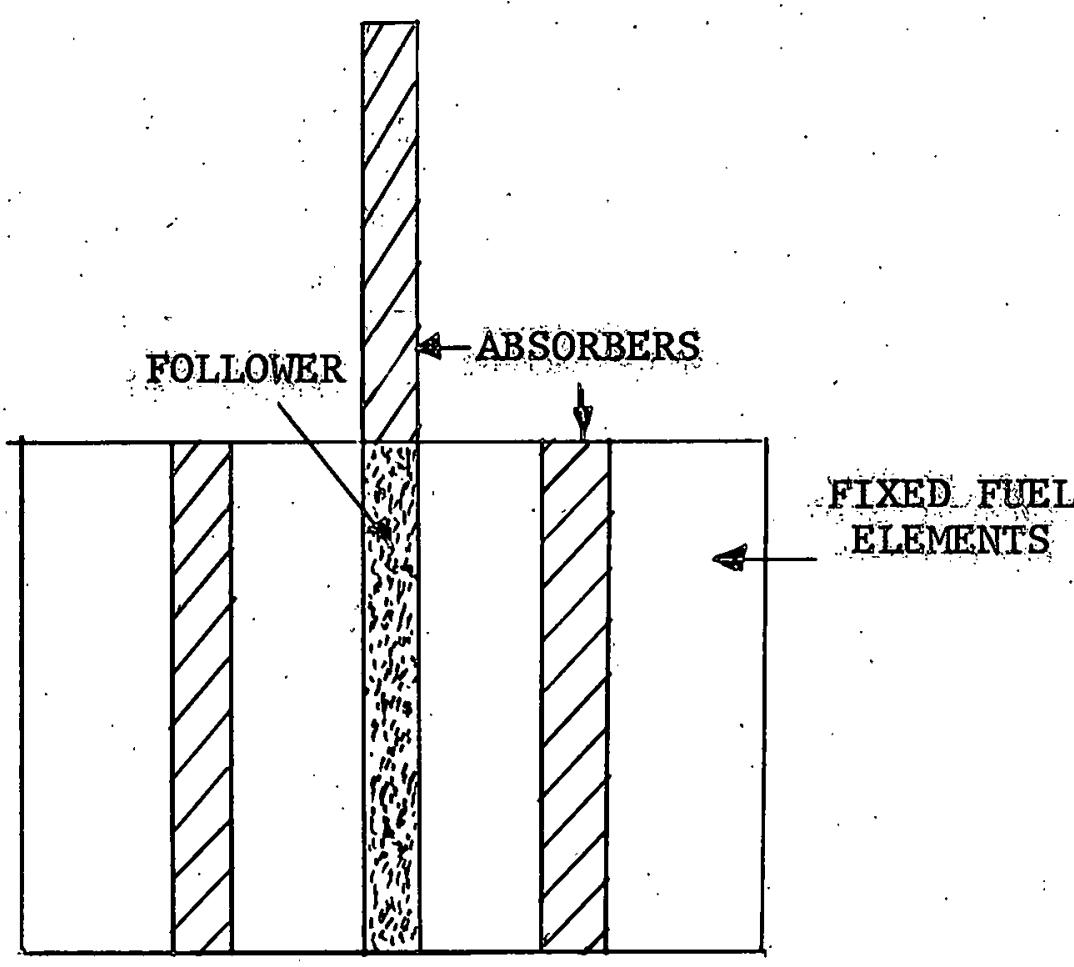

Case B. A control rod is pulled completely out of a core that contains a bank of other rods, partially withdrawn, as shown in Figure 2.

Since the bank has been raised from its original full in position, the net reactivity of the system increases. If $\mathrm{K}_{\mathrm{eff}}$ were equal to 1 originally, it is now equal to a value greater than 1 . Thus, any substitution of fuel of the follower for that in the fixed fuel element has a lesser effect on the reactor than in Case $A$, by the factor $1 / K_{\text {eff }}$. 
An additional effect is associated with the flux pattern. The neutron flux has become distorted to a shape involving a peaking in the lower region. Figure 3 shows typical plots of the flux distribution along the axis, in which the chopped cosine of Case A is compared with the distorted flux in Case B. The ratio of substitution reactivities for Cases $B$ and $A$ associated with flux distortions is given by perturbation theory as

$$
\frac{\rho_{\mathrm{B}}}{\rho_{\mathrm{A}}}=\frac{\int_{0}^{\mathrm{H}} \phi_{\mathrm{B}}^{2}(\mathrm{z}) \mathrm{d} z}{\int_{0}^{\mathrm{H}}(\mathrm{z}) \mathrm{dz}}
$$

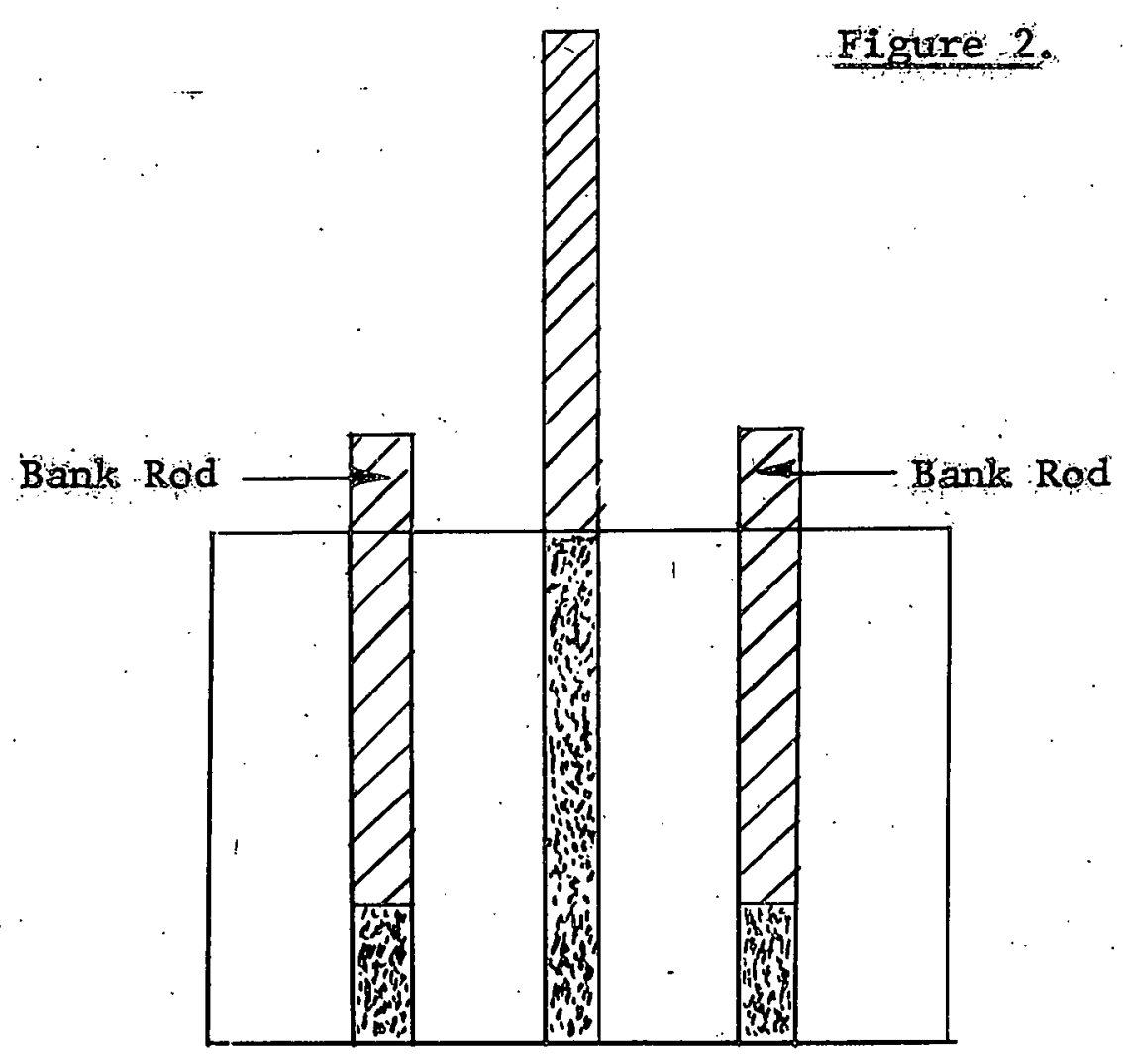




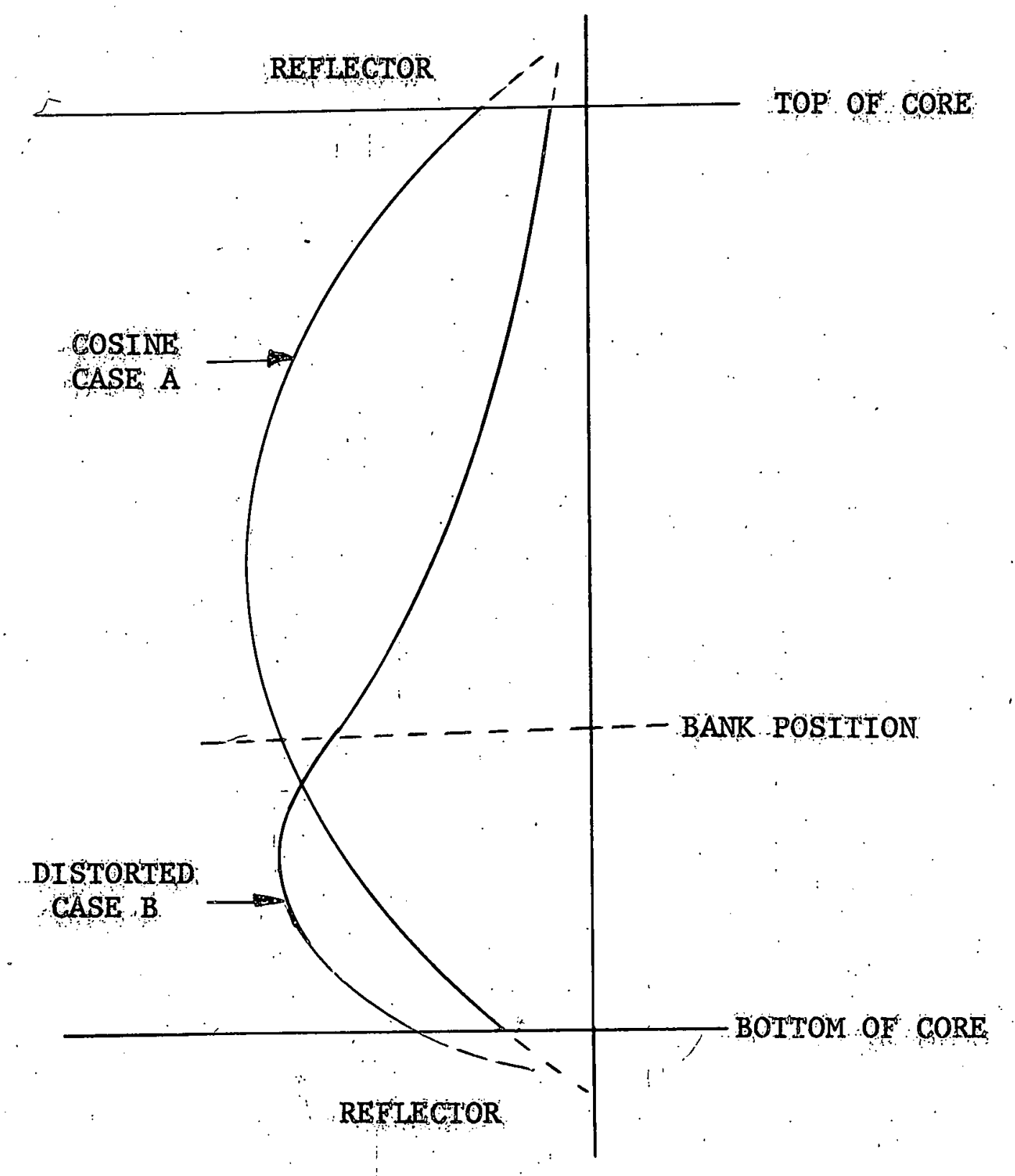

Figure 3

Axia1 Plux Distribution

$112 \quad 005$ 
where $\emptyset_{\mathrm{A}}(z)$ is the cosine and $\emptyset_{\mathrm{B}}$ is the new flux, the integrals of which can be taken as equal for essentially constant power normalization, $i$.e.,

$$
\int_{0}^{\mathrm{H}} \emptyset_{\mathrm{A}}(z) \mathrm{dz}=\int_{0}^{\mathrm{H}} \emptyset_{\mathrm{B}}(z) \mathrm{d} z
$$

The latter flux can be deduced from measurements or from window shade calculations.

Combining the reactor reactivity scale factor, the axial flux effect, and a possible off-center $\mathrm{J}_{0}^{2}$ weighting, the reactivity difference (follower vs fixed fuel) is

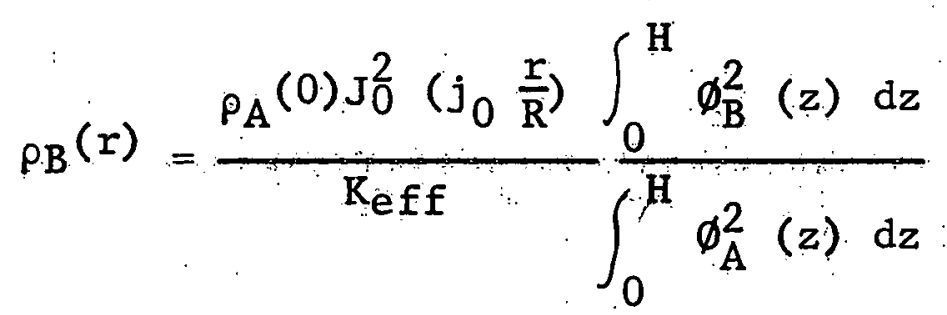

where the functional dependency of $\rho$ on $r$ and 0 refers to elements at $r$ and at 0 respectively.

Case c. The bank of rods is pulled out to a uniform distance, as shown in Figure 4.

Figtire 4

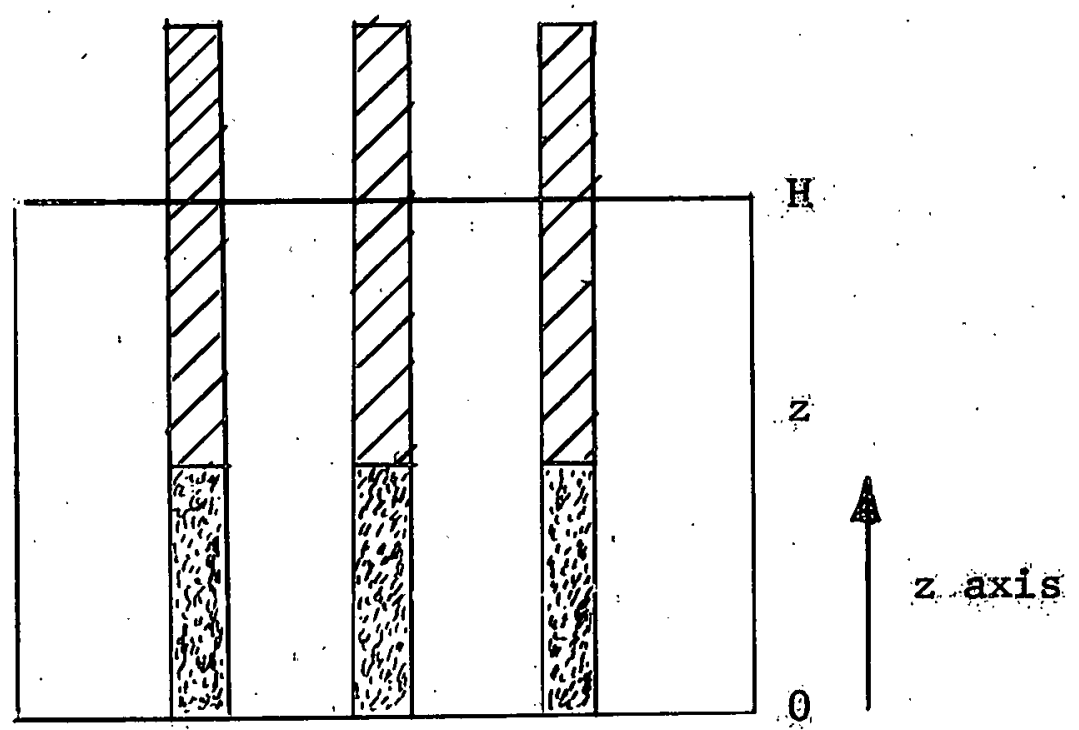


It is desired to estimate the reactivity difference due to followers, assuming the original interpolations or calculations (e.g. windowshade) were made assuming all fixed fuel elements Here, the perturbation effect is relevant only in the lower portion of the reactor. The value of substitution reactivity difference of the portion of the follower that is within the core (a distance $z$ ) bears a ratio to the reactivity difference value if the follower were fully in the core:

$$
\frac{\rho C^{(z)}}{\rho A}{ }^{(H)}=\frac{\int_{0}^{z} \phi_{C}^{2}(z) d z}{\int_{0}^{H} \phi_{A}^{2}(z) d z}
$$

where $\emptyset_{A}(z)$ is again the cosine distribution and $\emptyset_{C}(z)$ is the actual distorted distribution which is approximately as in Case $B$. Again, $1 / K_{\text {eff }}$ scaling and $J_{0}^{2}$ weighting are to be applied.

Compents.:

There are several weaknesses in the above procedure. For example, the distorted flux in the follower region of Case B is not necessarily equal to the windowshade plot, but is somewhat more peaked one should use experimental flux traverses along this axis, if available. Also, use of a perturbation theory implies an essentially critical reactor, whereas the reactor with bank out definitely has a $K_{\text {eff }}$ greater than unity.

The method is felt however, to contain most of the physical factors, exclusive of fine structure effects. 